\title{
Tendencias del empleo \\ en los años noventa en América Latina y el Caribe
}

\section{Jürgen Weller \\ Oficial de Asuntos \\ Económicos, \\ División de Desarrollo \\ Económico, CEPAL \\ jweller@eclac.cl}

Las reformas económicas aplicadas en la región en los decenios de 1980 y 1990 crearon expectativas, teóricamente fundamentadas, sobre una intensa generación de empleo y una mayor equidad en el mercado laboral. En este artículo se analiza la evolución del empleo y sus características durante el decenio de 1990. Se concluye que los problemas laborales actuales se deben a la falta de crecimiento económico y al uso menos intensivo de mano de obra, causados principalmente por las transformaciones de las actividades productoras de bienes transables. La modernización productiva de las empresas y la reestructuración sectorial en favor de las actividades terciarias contribuyeron a la segmentación del mercado de trabajo sobre la base del nivel educativo, ya que la demanda laboral se inclinó en favor de quienes habían cursado la enseñanza media y superior. Las personas con menos educación formal tuvieron menor acceso al empleo asalariado y se amplió la diferencia de salario entre los trabajadores calificados y los no calificados. Al mismo tiempo aumentó la diferencia de salarios entre las microempresas y las más grandes y, en el contexto de una flexibilización de las relaciones laborales, los indicadores de calidad del empleo tendieron a empeorar. Todas estas tendencias eran contrarias a las expectativas ligadas a las reformas. La reestructuración sectorial del empleo contribuyó a desencadenar un proceso de heterogeneización del mercado de trabajo que tiene diferentes dimensiones: generación simultánea e importante de empleo en los polos opuestos de la estructura laboral, mayor distancia entre lo formal y lo informal, diferenciación de las condiciones laborales de las empresas medianas y grandes, y diferenciación interna en las microempresas y en el trabajo por cuenta propia. 
I

\section{Introducción}

La evolución del mercado de trabajo entre 1950 y 1980 se caracterizó por un proceso de incorporación y de exclusión social: mientras una proporción creciente de la población económicamente activa logró incorporarse en actividades dinámicas, un contingente importante - que en el contexto de procesos entrelazados de atracción y expulsión salieron del sector agropecuario y en gran parte emigraron hacia las grandes ciudadessólo encontró ocupación en actividades de escasa productividad y baja remuneración (PREALC, 1991, pp. 9-14). Surgió así un consenso -incluso desde diferentes posiciones teóricas - de que, pese a que las tasas de desempleo abierto eran en promedio relativamente bajas, persistían en la región graves problemas laborales. Como fenómeno principal se destacó el subempleo (visible e invisible) que caracterizaba a grandes grupos de la agricultura campesina y del sector informal urbano. Durante la crisis de los años ochenta los problemas laborales se agudizaron, al reducirse la capacidad de los sectores formales para generar empleo productivo y concentrarse la mayor parte de los nuevos puestos de trabajo en el sector informal. Al mismo tiempo decaían la productividad laboral y los salarios reales.

Con las reformas económicas emprendidas durante los años ochenta y noventa se pretendía no sólo lograr una mayor estabilidad macroeconómica y tasas más altas de crecimiento del producto, sino también resolver los problemas estructurales de los mercados de trabajo de la región. Se partía del supuesto de que la subutilización de la fuerza de trabajo registrada en un período caracterizado por estrategias de crecimiento "hacia adentro" se debía principalmente a las distorsiones creadas en diferentes mercados de factores y bienes. Se trataría, primero, de la actitud antiexportadora que habría favorecido las actividades de sustitución de importaciones y producción de bienes y servicios no transables, en detrimento de las exportaciones caracterizadas por un uso más intensivo de mano de obra. En segundo lugar, las distorsiones en los mercados de trabajo y de capitales habrían abaratado el capital y encarecido la fuerza de trabajo, lo que habría tenido un impacto negativo en la demanda laboral. Por último, la orientación urbana de esta política habría relegado a segundo plano las actividades agropecuarias, que suelen hacer uso intensivo de mano de obra. La eliminación de estas distorsiones en los mercados de factores y de bienes implicaría la reasignación de los recursos hacia actividades productoras de bienes exportables y tecnologías de uso más intensivo de mano de obra, por lo cual aumentaría la demanda laboral. Además, el conjunto de las reformas tendría un impacto positivo en el crecimiento económico, variable fundamental para una mayor generación de empleo.

Por la abundancia relativa de la mano de obra poco calificada, el aumento de la demanda laboral se concentraría en este sector de la fuerza de trabajo. De esta manera se elevarían los salarios relativos de la mano de obra poco calificada, lo que tendría efectos distributivos positivos. Efecto positivo tendría también el reforzamiento de la empresa pequeña y mediana, ya que se sostenía que las distorsiones anteriores habían favorecido a las empresas grandes en perjuicio de las pequeñas. Por último, la eliminación de algunas regulaciones laborales y el abaratamiento de otras fomentaría la formalización de las relaciones de trabajo y reduciría el peso relativo del sector informal en el empleo.

Durante los años ochenta y noventa las reformas orientadas a eliminar las distorsiones en los diferentes mercados de la región avanzaron considerablemente (Morley, Machado y Pettinato, 1999). Hasta ahora, las evaluaciones de la evolución de los mercados de trabajo de la región en los años noventa, califican de decepcionantes los resultados de estas reformas. ${ }^{1}$ Es bastante común la apreciación de que la situación de los

\footnotetext{
1 Véanse CEPAL (1997), Thomas (1997), Lora y Olivera (1998) y Weeks (1999). También en las publicaciones de la OIT se subrayan las deficiencias de la generación del empleo, tanto en cantidad como en calidad, pero se observa que los países que llevaron a cabo las reformas más tempranamente tuvieron mejores resultados (por ejemplo, en OIT, 1999b).
} 
mercados de trabajo es el principal problema de los países latinoamericanos y del Caribe, y con frecuen- cia se dice que la región se encuentra en una dinámica de "crecimiento sin empleo".

\section{II}

\section{La evolución global de los mercados de trabajo durante los años noventa}

En esta sección se presentan algunas tendencias globales de los mercados de trabajo de la región durante los años noventa y luego se describen algunos aspectos que reflejan la elevada heterogeneidad entre los países. El propósito es evaluar el mercado laboral con respecto a las expectativas generadas por las reformas económicas y las necesidades reveladas de los hogares de la región.

El gráfico 1 muestra la evolución de algunos indicadores del mercado laboral, para la región en su conjunto. Se presentan sus medianas, para evitar que los países más grandes (en el caso de promedios ponderados) o algunas situaciones extremas (en el caso de promedios simples) influyan desproporcionadamente en los datos. Se trata de la tasa global de participación (TGP), la tasa de ocupación (TO), el salario medio real en el sector formal (SmedR) y el salario mínimo real (SminR). Entre paréntesis se presenta el número de países para los cuales se dispone de la información correspondiente.

La tasa global de participación presenta una tendencia ascendente, no libre de oscilaciones. En cambio, la tasa de ocupación después de un aumento al inicio del decenio de 1990 descendió marcadamente durante los años siguientes, y el nuevo aumento hacia 1997 y 1998 no bastó para reducir la diferencia con respecto a la oferta laboral, lo que se tradujo en tasas más altas de desempleo (líneas rayadas del gráfico). Además, el nuevo empleo se concentró más que proporcionalmente en actividades de baja productividad. ${ }^{2}$ La evolución de los salarios fue algo más favorable, pues aumentaron durante los primeros cinco años de la década, aunque se estancaron después por efecto de la elevada volatilidad económica, con un crecimiento

\footnotetext{
${ }^{2}$ En la mediana de 12 países, la participación del sector informal en el empleo urbano subió de $43.5 \%$ a $47.9 \%$ (cálculo propio basado en OIT, 1999a).
}

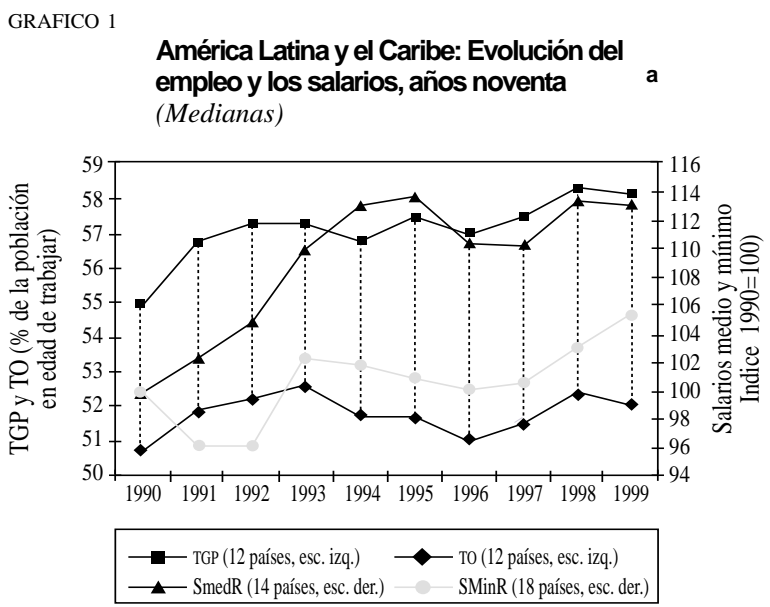

Fuente: CEPAL (2000b) y datos oficiales de los países.

a Las tasas de participación y de ocupación se refieren, en la mayoría de los países, a las áreas urbanas.

anual de poco más de $1 \%$, superior a la tasa del decenio anterior, pero no por mucho. De esta manera, a fines del decenio de 1990 una serie de países todavía no había alcanzado los niveles de 1980 (CEPAL, 2000b, cuadro VI.4).

Respecto a los salarios mínimos, se mantenían las políticas cautelosas que se habían aplicado ya en el decenio anterior; sólo durante los últimos años se registraron algunos aumentos reales, que se tradujeron en un aumento anual de alrededor de medio por ciento como promedio para la década.

¿Cómo se presenta la generación de empleo en los años noventa con una perspectiva histórica? El cuadro 1 muestra que la tasa de generación de empleo creció entre los años cincuenta y setenta, y decayó en las décadas siguientes. La elasticidad-empleo del producto de los años noventa no se diferencia del promedio regional de todo el período 1950-1997. A este ni- 
CUADRO 1

América Latina y el Caribe: Crecimiento del producto, el empleo y la elasticidad-empleo del producto, 1950-1999

\begin{tabular}{lcccc}
\hline Período & $\begin{array}{c}\text { Crecimiento } \\
\text { económico }\end{array}$ & $\begin{array}{c}\text { Crecimiento } \\
\text { del empleo }\end{array}$ & $\begin{array}{c}\text { Elasticidad-empleo } \\
\text { del producto }\end{array}$ & $\begin{array}{c}\text { Crecimiento del } \\
\text { empleo asalariado } \\
\text { asalariado del producto }\end{array}$ \\
\hline Años cincuenta & 5.1 & 1.9 & 0.4 & 2.5 \\
Años sesenta & 5.7 & 2.3 & 0.4 & 2.7 \\
Años setenta & 5.6 & 3.8 & 0.7 & 4.7 \\
Años ochenta & 1.2 & 2.9 & 2.6 & 2.4 \\
Años noventa & 3.8 & 2.2 & 0.6 & 2.2 \\
Años cincuenta a noventa & 4.3 & 2.7 & 0.6 & 0.5 \\
\hline
\end{tabular}

Fuente: Elaboración propia basada en información de la CEPAL y la Organización Internacional del Trabajo (OIT).

a $1990-1997$.

vel de agregación no se registran cambios fundamentales ni hacia un mayor uso relativo de la fuerza laboral en comparación con las tendencias a largo plazo de los decenios anteriores (como se había sostenido en favor de las reformas) ni hacia una menor intensidad de empleo (como se criticó durante los años noventa) y no se puede hablar de un crecimiento sin empleo (jobless growth). De esta manera, la causa principal (si bien no la única) del aumento del desempleo abierto en los años noventa habría sido el flojo crecimiento económico, insuficiente para absorber la creciente oferta laboral.

Para simplificar, los mercados de trabajo de la región pueden analizarse en dos segmentos, respondiendo el uno en mayor grado a la dinámica de la demanda laboral y el otro a la dinámica de la oferta. Debido a esta segunda dinámica y a su peso estructural en países que carecen de sistemas de prestaciones en caso de desempleo, a largo plazo - y en la comparación entre países- la generación del empleo se correlaciona estrechamente con la evolución de la oferta. Esto vale, sobre todo, para el empleo en su conjunto. De esta manera, el crecimiento del empleo presentado en el cuadro 1 -ascendente hasta los años setenta, descendente después - refleja principalmente la evolución de la oferta y, sobre todo, su componente demográfico que es el que mayor peso tiene $-\mathrm{y}$ no las diferencias en el uso del factor trabajo de parte de modelos de crecimiento de diferente índole.

Nuevamente simplificando, puede usarse el empleo asalariado como variable vicaria para apreciar la evolución del segmento determinado principalmente por la demanda - debido a que refleja la disposición de las empresas y del sector público de "pagar un precio"- y el trabajo por cuenta propia para aquel determinado principalmente por la oferta, ya que son las principales categorías de ocupación de los respectivos segmentos. La comparación histórica revela una evolución relativamente floja del empleo asalariado (véase nuevamente el cuadro 1). Mientras que entre los años cincuenta y setenta el empleo asalariado creció con tasas más elevadas que el empleo en su conjunto, y subió su participación en el empleo total, en los años noventa el empleo en esta categoría creció solamente a la misma tasa que el empleo en su conjunto. ${ }^{3}$ Sólo en los años ochenta su evolución fue peor, con una contracción de su participación en el empleo total. Hay que tomar en cuenta que la presión de la oferta también puede incidir en la generación de cierto tipo de empleo asalariado, sobre todo en las microempresas, ${ }^{4}$ así como hay también empleo por cuenta propia que responde más bien a las preferencias y las oportunidades - de ingresos u otros- que a la mera necesidad, característica del segmento, determinada principalmente por la oferta, de generar ingresos mínimos para la sobrevivencia.

$\mathrm{Al}$ analizar las tendencias laborales principales de los años noventa en mayor detalle, se advierte que, en esta década, la oferta laboral no mostró ningún quiebre con respecto de las tendencias anteriores. Se man-

\footnotetext{
${ }^{3}$ La evolución relativa del empleo asalariado sería más desfavorable si se incorpora la información correspondiente a los años 1998 y 1999, ya que en ambos años el empleo asalariado creció a tasas más bajas que el conjunto de las demás categorías de ocupación (véanse los volúmenes correspondientes del Estudio Económico de América Latina y el Caribe de la CEPAL).

${ }^{4} \mathrm{El}$ hecho de que la generación del empleo en los años ochenta fue baja en términos relativos, pero más alta que en los noventa en términos absolutos, indica que en situaciones de crisis económica también el empleo asalariado refleja en forma importante la presión de la oferta. De hecho, la mayor parte del empleo asalariado se generó en las microempresas.
} 
CUADRO 2

\section{América Latina y el Caribe (17 países): Crecimiento anual del empleo por categoría de ocupación y contribución de las categorías a la generación de empleo, 1990-1997}

\begin{tabular}{|c|c|c|c|c|}
\hline \multirow[t]{2}{*}{ Categoría de ocupación ${ }^{a}$} & \multicolumn{2}{|c|}{ Crecimiento anual } & \multicolumn{2}{|c|}{ Contribución a nuevos empleos } \\
\hline & Promedio ponderado & Mediana & Promedio ponderado & Mediana $^{b}$ \\
\hline Asalariados, total (17) & 2.2 & 2.7 & 51.8 & 62.1 \\
\hline Asalariados privados (13) & 2.2 & 3.2 & 49.7 & 52.6 \\
\hline Asalariados públicos (13) & 0.7 & 0.6 & 2.0 & 2.5 \\
\hline Trabajadores por cuenta propia (17) & 2.8 & 3.1 & 35.9 & 34.2 \\
\hline Servicio doméstico (13) & 3.9 & 3.5 & 9.9 & 3.9 \\
\hline Otras categorías $(17)$ & 0.4 & 0.5 & 0.6 & 2.4 \\
\hline Total (17) & 2.2 & 3.4 & 100.0 & 100.0 \\
\hline
\end{tabular}

Fuente: Elaborado por el autor, sobre la base de encuestas de hogares de cada país.

a Entre paréntesis se indica el número de países con información disponible.

b El total de las contribuciones no suma necesariamente cien.

tuvieron las tendencias de un aumento decreciente de su componente demográfico, ${ }^{5}$ así como el incremento de la tasa de participación, por efecto de la mayor participación de las mujeres en los mercados de trabajo. ${ }^{6}$ Así, la presión de la oferta laboral total se mantuvo por encima de su componente demográfico. En cuanto a los aspectos cualitativos, se observa que los dos componentes de la oferta laboral que suelen identificarse como básicos para la formación de los recursos humanos - la educación formal y la experiencia laboral- siguieron procesos ascendentes. Por una parte, aumentó la matrícula en la educación secundaria y terciaria y, con la incorporación laboral de jóvenes con más años de educación formal, subieron los niveles medios de instrucción de la fuerza de trabajo, aunque con importantes deficiencias cuantitativas y cualitativas (Duryea y Székely, 1998). Por otra parte, la disminución relativa de las cohortes más jóvenes en la población en edad de trabajar se tradujo en un aumento de los niveles medios de experiencia laboral. En conclusión, la mayor parte de los elementos cuantitativos y cualitativos principales de la oferta laboral respondían a tendencias de largo plazo, por lo que no se registraron cambios en reacción con eventos recientes como las reformas económicas. El único indicador que

\footnotetext{
${ }^{5}$ La expansión anual de la población en edad de trabajar bajó de $2.5 \%$ a principios de los años ochenta a $2.0 \%$ hacia fines de los años noventa (cálculo propio basado en CEPAL/CELADE, 1999).

${ }^{6}$ Véase CEPAL (2000b, anexo estadístico) para la evolución diferenciada de la participación laboral según sexo.
}

sí puede reflejar reacciones a corto plazo $-\mathrm{y}$ de hecho lo hace a través del ciclo coyuntural- es la tasa de participación, cuya tendencia, sin embargo, tampoco mostró ningún tipo de quiebre.

La relativa debilidad de la demanda laboral se aprecia en el cuadro 2 que presenta la evolución desagregada del empleo en el período 1990-1997 para las diferentes categorías de ocupación y para la región en su conjunto.

A nivel regional el empleo creció a una tasa anual de $2.2 \% .{ }^{7}$ El empleo en algunas categorías que en gran parte representan condiciones de trabajo e ingresos desfavorables - como el trabajo por cuenta propia y el servicio doméstico- aumentó más que el empleo asalariado. Entre los asalariados, el crecimiento del empleo público fue inferior al del empleo en su conjunto debido a los procesos de privatización y las políticas fiscales más restrictivas. Se mantuvo el número de los trabajadores familiares no remunerados, con lo que se prolongó la tendencia a largo plazo de una reducción de su peso relativo en la estructura del empleo, vinculada sobre todo con la contracción relativa de la economía campesina. Al empleo asalariado corresponde alrededor de la mitad de los nuevos empleos (algo más en la mediana), y otro tercio al trabajo por cuenta propia. En el gráfico 2 se observa para cuatro países el vínculo entre los cambios en la tasa de crecimiento

\footnotetext{
${ }^{7}$ La tasa de crecimiento del empleo de $2.9 \%$ anual que se menciona en otras publicaciones para el mismo período (OIT, 1998b; CEPAL, 2000a, p. 75) se refiere exclusivamente al empleo no agrícola.
} 
Argentina, 1991-1997

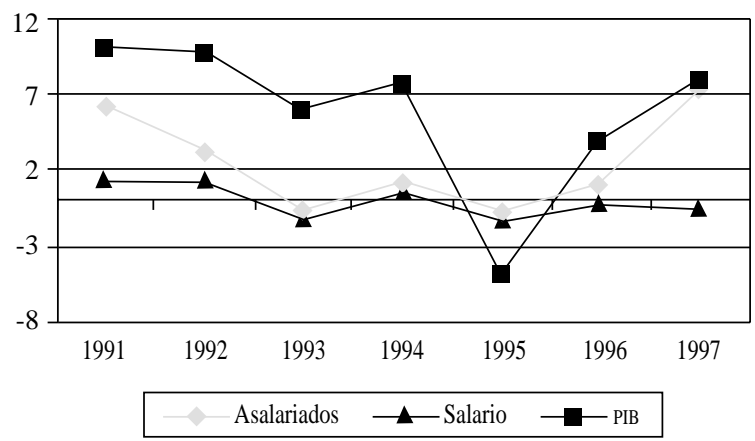

Chile, 1987-1997

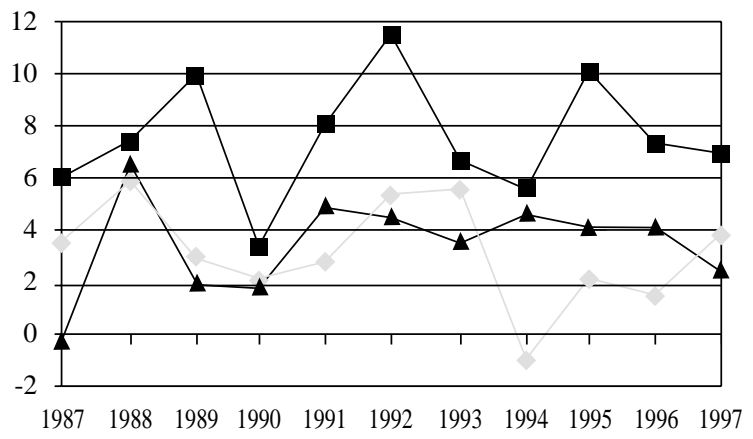

$\longrightarrow$ Asalariados $\longrightarrow$ Salario $\longrightarrow$ - $\mathrm{PIB}$
Brasil, 1991-1997

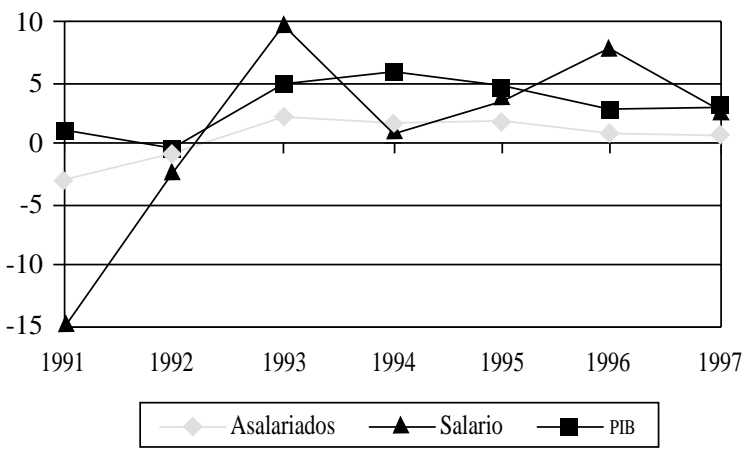

México, 1992-1997

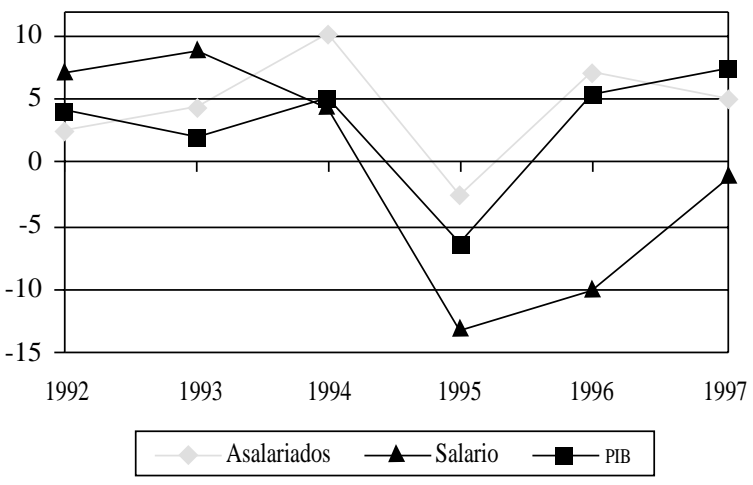

Fuente: Elaborado por el autor, sobre la base de antecedentes de la CEPAL.

económico y los cambios en el empleo asalariado y en los salarios. ${ }^{8}$

Un elemento importante para explicar la creación de empleo - tanto por cantidad como por sus características - fue la evolución a nivel sectorial. Durante los años noventa se mantuvieron las tendencias a largo plazo de reducción del empleo en el sector primario y de expansión en el terciario, mientras que parece haber llegado a su fin la expansión relativa del empleo del sector secundario (cuadro 3).

Entre 1990 y 1997, el empleo manufacturero se expandió a una tasa anual de $1.3 \%$. En los países

\footnotetext{
${ }^{8}$ Estimaciones econométricas realizadas en el marco del proyecto confirmaron la importancia del crecimiento económico para la generación de empleo; véase Weller (2000, cap. 4). Véase también Lora y Olivera (1998).
}

medianos y grandes contrasta el estancamiento o incluso la contracción del empleo manufacturero en Argentina, Brasil y Colombia, con la expansión significativa de México. El empleo agropecuario descendió incluso en términos absolutos, lo que acentúa la tendencia anterior hacia una reducción relativa del empleo en este sector.

La construcción - actividad de uso muy intensivo de mano de obra y muy sensible a la situación coyuntural de la economía - contribuyó a nivel regional casi a un $10 \%$ del nuevo empleo. Pero fueron los diversos renglones del sector terciario los que registraron la evolución más dinámica en términos de generación de empleo. Por un lado, se destacan algunas ramas de la actividad vinculadas con la transformación de las economías de la región, sobre todo la rama de servicios financieros, seguros, servicios a empresas y bienes raíces y los servicios básicos (electricidad, gas 
CUADRO 3

América Latina y el Caribe (17 países): Crecimiento y contribución al empleo nuevo, por rama de actividad, años noventa

(En porcentajes)

\begin{tabular}{|c|c|c|c|c|c|c|}
\hline \multirow[t]{3}{*}{ 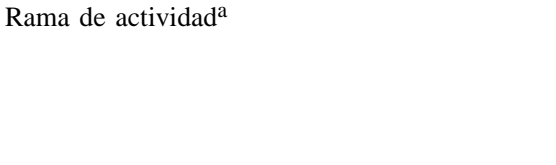 } & \multicolumn{3}{|c|}{ Crecimiento anual } & \multicolumn{2}{|c|}{$\begin{array}{c}\text { Contribución a nuevos } \\
\text { empleos }\end{array}$} & \multirow{3}{*}{$\begin{array}{l}\text { Variación de } \\
\text { participación } \\
\text { del empleo } \\
\text { femenino }^{d}\end{array}$} \\
\hline & \multirow{2}{*}{$\begin{array}{c}\text { Valor } \\
\text { agregado }^{b}\end{array}$} & \multicolumn{2}{|c|}{ Empleo } & \multirow{2}{*}{$\begin{array}{l}\text { Promedio } \\
\text { ponderado }\end{array}$} & \multirow[t]{2}{*}{ Mediana $^{\mathrm{c}}$} & \\
\hline & & $\begin{array}{l}\text { Promedio } \\
\text { ponderado }\end{array}$ & Mediana & & & \\
\hline Agricultura (13) & 2.5 & -0.6 & -1.2 & -7.0 & -6.0 & 0.9 \\
\hline Industria manufacturera (17) & 3.5 & 1.3 & 1.3 & 8.7 & 6.8 & 1.6 \\
\hline Comercio, restaurantes y hoteles (17) & 3.8 & 4.0 & 5.7 & 32.3 & 34.2 & 0.5 \\
\hline Servicios financieros $^{\mathrm{e}}(15)$ & 3.4 & 6.6 & 7.8 & 10.8 & 11.0 & -1.1 \\
\hline Servicios básicos ${ }^{f}(17)$ & 5.8 & 4.8 & 4.8 & 12.6 & 7.6 & 2.6 \\
\hline Servicios sociales, comunales y personales (17) & 2.2 & 2.9 & 2.8 & 37.2 & 31.8 & 0.9 \\
\hline Otros $(17)$ & $\ldots$ & -3.0 & -2.7 & -2.9 & -0.1 & $\ldots$ \\
\hline Total (17) & 3.8 & 2.2 & 3.4 & 100.0 & 100.0 & 1.5 \\
\hline
\end{tabular}

Fuente: Elaborado por el autor sobre la base de cifras oficiales de los países, datos de la CEPAL y de la OIT (1998a).

a Entre paréntesis se indica el número de países con información disponible.

b Se refiere a 31 países de la región; los 17 países con información sobre el crecimiento del empleo en 1995 representaban $98.3 \%$ del PIB regional.

c El total de las contribuciones no necesariamente suma cien.

d En puntos porcentuales; mediana de 13 países.

e Incluye servicios financieros, seguros, servicios a empresas y bienes raíces.

f Incluye electricidad, gas y agua, así como comunicaciones, transporte y almacenamiento.

y agua; transporte, almacenamiento y comunicaciones). Por el otro, en la rama de comercio, restaurantes y hoteles se encuentran tanto actividades muy dinámicas durante los años noventa (grandes tiendas y supermercados, comercio exterior, turismo) como el comercio informal típico. Un alto grado de heterogeneidad caracteriza también a los servicios sociales, comunales y personales. En el plano regional, estas dos últimas ramas contribuyeron aproximadamente $70 \%$ de los empleos generados en los años noventa.

Un importante elemento en la evolución del empleo ha sido el aumento bastante general de la participación laboral de la mujer (véase la última columna del cuadro 3). Este aumento se dio en los sectores con una participación femenina tradicionalmente alta (los servicios, el comercio, en menor grado también la industria manufacturera) y también en aquellos donde esta participación suele ser baja. Asimismo, se aprecia tanto en ramas poco dinámicas en la generación de empleo durante los años noventa como en los sectores en que se concentró la creación de empleo, siendo la única excepción los servicios básicos, debido al fuerte aumento del empleo en el transporte, donde predomina el empleo de hombres.
El nuevo empleo de los años noventa ha acelerado el proceso vigente desde décadas anteriores de un aumento del sector terciario en la estructura del empleo. Hacia finales de la década, en 12 de 14 países con información a nivel nacional las actividades terciarias absorbían más del $50 \%$ del empleo; en tres países incluso más del 60\%. En 1997, para el conjunto de la región, un $54.9 \%$ de los ocupados trabajaban en actividades terciarias. ${ }^{9}$ También se aceleró la reducción del empleo agropecuario. En décadas anteriores había crecido a tasas más bajas que el empleo en su conjunto, pero en el decenio de 1990, en 8 de 13 países con información disponible y a nivel regional, incluso mostró un decrecimiento en cifras absolutas. En consecuencia, en la región la participación del sector bajó a $23.6 \%$. Hacia fines de la década el empleo manufacturero representaba sólo $13.5 \%$ del empleo total de la región, mientras la construcción aportaba otro $6 \%$.

La evolución del empleo encuentra su contrapartida en la evolución de la productividad laboral. Des-

\footnotetext{
${ }^{9}$ Incluye los servicios básicos.
} 
pués de su fuerte caída en la década anterior, la productividad laboral media volvió a subir en los años noventa sin que hasta 1997 hubiera alcanzado el nivel de 1980. ${ }^{10} \mathrm{Si}$ se comparan las tasas de crecimiento del valor agregado y del empleo a nivel sectorial (véase nuevamente el cuadro 3), se observa que en los sectores que engloban principalmente actividades de producción de bienes transables - los sectores primario y secundario- se elevó la productividad, pero apenas el empleo, mientras que en el sector terciario, caracterizado por actividades no transables, aumentó el empleo, pero no la productividad. Esto obedece al hecho de que la mayor inserción de la región en los mercados globales no se basó - como se esperaba- en un uso de factores que reflejara la abundancia relativa de la fuerza de trabajo y el capital. En muchos mercados, cada vez más integrados, se imponen normas de competitividad cuyos parámetros se definen en gran parte por tecnologías ahorradoras de mano de obra. Por otro lado, en productos en que la competitividad, en la terminología de Porter (1991), es impulsada más bien por los factores básicos (basic factor driven) y en que gravita fuertemente la disponibilidad de una abundante fuerza laboral de niveles de calificación relativamente bajos, hay otras regiones, aparentemente, que aventajan a América Latina. ${ }^{11}$ La evolución de la productividad sectorial también indica la debilidad de la generación de empleo productivo ya que sugiere que una gran parte de los nuevos puestos de trabajo ha surgido en actividades del sector terciario de baja productividad. ${ }^{12}$

Frente a este panorama a nivel regional, debe señalarse la gran heterogeneidad de los resultados obtenidos por los distintos países de la región. El cuadro 4 muestra esos resultados para 17 países. En él se resume la evolución de cinco variables: las variaciones de la tasa de desempleo, la tasa de ocupación, el salario

\footnotetext{
${ }^{10}$ En el bienio 1998-1999 la productividad laboral media volvió a decrecer.

11 Véase Wood (1997). De la situación sometida a presiones de competencia tanto desde arriba como desde abajo, aparentemente han escapado por lo menos en parte algunos países del norte de la región (México y países de América Central y del Caribe). Si bien las tendencias mencionadas no han estado ausentes en ellos la creciente integración con el mercado norteamericano (aprovechando la cercanía geográfica y condiciones comerciales especiales) permitió la expansión de actividades de uso intensivo de mano de obra (maquila, ciertos productos agrícolas).

12 Antes de 1980 el sector terciario fue el principal generador de empleo, pero en el contexto de una productividad laboral creciente. Según cálculos de la oIT, seis de cada 10 nuevos puestos de trabajo urbanos de los años noventa surgieron en el sector informal (OIT, 1999b).
}

real en el sector formal y la productividad laboral y, por último, la relación entre el crecimiento del empleo asalariado y el empleo en su conjunto (como indicador de la fuerza relativa de la demanda laboral).

Se registran grandes diferencias entre los países, con un desempeño relativamente favorable en Chile, El Salvador, Panamá, la República Dominicana y en menor grado en Costa Rica, México, Perú y Uruguay, y poco satisfactorio en Argentina, Brasil, Colombia, Paraguay y Venezuela. ${ }^{13}$ El crecimiento económico representó un papel muy importante para estos resultados como se ve en el gráfico 3, para el cual se construyó un índice que cuantifica los datos de los 17 países en los años noventa respecto a las cuatro primeras variables del cuadro $4 .{ }^{14}$ Se calcularon índices para cada variable, para los cuales se atribuyó un valor entre 0 y 1 a los países según su distancia del país con el mejor (1) y el peor (0) desempeño, y se sacó el promedio de estos cinco índices para calcular el índice del desempeño laboral.

Los que se distancian de esta alta correlación entre el crecimiento económico y el índice de desempeño laboral son, por un lado, Argentina y Perú donde las reformas llevadas a cabo con gran velocidad al inicio

GRAFICO 3
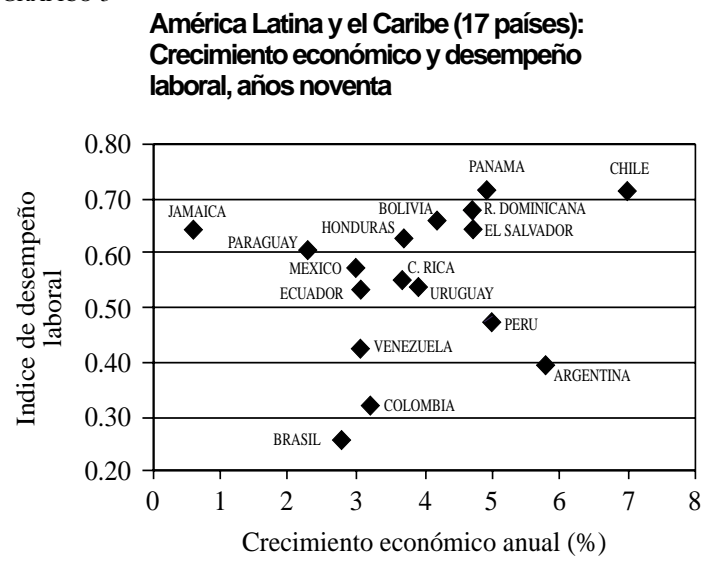

Fuente: Elaborado por el autor sobre la base de antecedentes de la CEPAL e información oficial de los países.

\footnotetext{
${ }^{13}$ Véase CEPAL (2000b, cap. 6) para le evolución detallada del desempleo, los salarios medios y los salarios mínimos a nivel de los países.

${ }^{14}$ Se excluyó la productividad laboral para evitar la correlación aparente que se generaría al introducir la variable del crecimiento económico a los valores correspondientes a ambos ejes del gráfico. Por lo tanto, la posición relativa de los países difiere ligeramente de la que presenta el cuadro 4.
} 
CUADRO 4

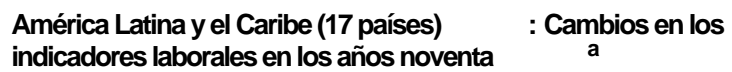

\begin{tabular}{|c|c|c|c|c|c|}
\hline País y año umbral de las reformas & Desempleo & Nivel de ocupación & Empleo asalariado & Salario real & Productividad laboral \\
\hline Argentina, 1990 & - & - & + & $=$ & + \\
\hline Bolivia, 1986 & + & + & - & + & - \\
\hline Brasil, 1989 & - & - & $=$ & + & + \\
\hline Chile, 1974 & + & + & + & + & + \\
\hline Colombia, 1992 & - & $=$ & - & + & + \\
\hline Costa Rica, 1987 & $=$ & + & $=$ & + & + \\
\hline Ecuador, 1992 & - & + & - & + & $=$ \\
\hline El Salvador, 1990 & + & + & + & $=$ & + \\
\hline Honduras, 1992 & + & + & $=$ & - & - \\
\hline Jamaica, 1991 & $=$ & - & + & + & - \\
\hline México, 1989 & - & + & + & + & $=$ \\
\hline Panamá, n.d. & + & + & + & + & + \\
\hline Paraguay, 1990 & - & + & - & + & - \\
\hline Perú, 1991 & $=$ & + & - & + & + \\
\hline Uruguay, 1979 & - & + & $=$ & + & + \\
\hline Venezuela, 1991 & - & + & - & - & - \\
\hline
\end{tabular}

Fuente: Elaboración propia.

a Los años umbrales de las reformas se refieren a los años en que el índice de reformas, calculado por Morley, Machado y Pettinato (1999) registró su mayor aumento. La evaluación del desempeño laboral se refiere a los cambios entre inicios de los años noventa y 1998 (en algunos casos: 1997). + significa cambio favorable, - significa cambio desfavorable, = significa sin cambio o cambio muy pequeño. Columna 1: Variación porcentual de la tasa de desempleo. Columna 2: Variación de la tasa de ocupación, en puntos porcentuales. Columna 3: Crecimiento del empleo asalariado respecto al crecimiento del empleo en su conjunto. Columna 4: Variación porcentual del salario medio real en el sector formal. Columna 5: Variación porcentual de la productividad laboral media.

de la década tuvieron un impacto negativo en varios aspectos del mercado de trabajo y, por el otro lado, Jamaica donde el resultado ha sido mejor que lo esperado, gracias a una generación de empleo asalariado privado relativamente fuerte en actividades terciarias, un mejoramiento de los salarios reales y un estancamiento del desempleo, si bien a alto nivel.

Algunos de los países que aplicaron las reformas más tempranamente (Chile, Bolivia, Costa Rica) se encuentran entre los países con una trayectoria laboral relativamente favorable, sin salirse de la tendencia. Esto concuerda con los resultados de ejercicios econométricos que indicaban que las reformas económicas habían influido de manera ligeramente positiva en el crecimiento, por lo que por esta vía habrían tenido un impacto favorable en el empleo. ${ }^{15}$ Sin embargo, contra toda expectativa, las reformas aparentemente habrían reducido la intensidad de uso de la mano de obra en el crecimiento económico, con consecuencias negativas para la generación de puestos de trabajo. ${ }^{16}$

15 Véase Stallings y Peres (2000), también BID (1997).

16 Véase Weller (2000, sección 4.2).
Este proceso no fue transitorio, ya que la reducción de la intensidad de uso laboral parece haberse mantenido a más largo plazo. A nivel agregado, la apertura comercial ha tenido un impacto negativo en la intensidad de uso de la fuerza trabajadora. Finalmente, se detectó una correlación positiva entre el tipo de cambio real y la intensidad de uso laboral, lo que en vista de las tendencias de apreciación registradas durante la mayor parte de los años noventa en la región hace considerarla como otro factor que influyó negativamente en la demanda laboral.

De esta manera, la aparente contradicción entre el impacto negativo de las reformas en el empleo, identificado en la mayoría de los estudios, y la evolución relativamente más favorable que detectó la огт (1999b) en los mercados de trabajo de los países de reformas tempranas, se explicaría por sus resultados más positivos en términos de crecimiento económico, mientras que en los otros países la reducción de la intensidad de uso de la mano de obra generó resultados más negativos.

Se puede concluir que la generación de empleo durante los años noventa fue decepcionante, tanto en la comparación histórica con las décadas entre los años cincuenta y los setenta (baja generación relativa de 
empleo asalariado) como con respecto de las expectativas cifradas en las reformas sobre la intensidad de generación de empleo y su composición sectorial y de las necesidades de los hogares (como se expresa en el desempleo creciente), si bien con importantes diferen- cias entre países. Los orígenes de este fenómeno fueron la debilidad del crecimiento económico y la baja demanda laboral en las ramas productoras de bienes transables, en el contexto de su integración con los mercados internacionales.

\section{III}

\section{El sesgo de la demanda laboral}

Según se vio anteriormente, como justificación teórica de las reformas se había argumentado que los cambios en la estructura productiva y en los sectores favorecerían la demanda de mano de obra no calificada, debido a la abundancia relativa de este factor en los países de la región, lo cual influiría a su vez en una disminución de la diferencia de salarios entre el personal de alto y de bajo nivel de calificación. En consonancia con esas expectativas, en los años ochenta se redujo en la mayoría de los países de América Latina y el Caribe la diferencia entre los salarios medios de las personas con educación universitaria y las con educación primaria (Psacharopoulos y Ng, 1992, p. 15).

Sin embargo, varios estudios sobre el caso chileno han puesto en duda que estas tendencias hayan de persistir después de la etapa de reforma y en un cuadro de mayor crecimiento económico. ${ }^{17}$ De hecho, si se compara el ascenso educativo de la población en edad de trabajar con el aumento del nivel de instrucción de las personas ocupadas se observa que en la mayoría de los países los grupos con niveles educativos medios altos (entre 10 y 12 años de estudio) y altos (13 y más años de estudio) aumentaron su participación en el empleo más que en la población en edad de trabajar en su conjunto; ocurrió lo contrario en los grupos de niveles educativos más bajos (Weller 2000, cuadro 6.1). Esta evolución diferenciada de la estructura del empleo según la escolaridad sería una primera confirmación de que durante los años noventa la demanda laboral se orientó a favor del personal calificado y no a favor del no calificado.

Si existe esta orientación, debería reflejarse en diferencias de la generación de empleo asalariado y no asalariado según niveles educativos. Como el empleo asalariado es el reflejo más fiel de la demanda labo-

\footnotetext{
${ }^{17}$ Para el caso chileno, sobre todo, Robbins (1994 y 1996) identi-
} ficó una tendencia hacia el aumento de la diferencia de salarios.. ral, las diferencias de este tipo estarían indicando que el mayor aumento del empleo de personal calificado realmente se debe a las preferencias de la demanda. El gráfico 4 ilustra este aspecto. En él se presenta para siete países la diferencia entre la contribución de los asalariados y los no asalariados a los nuevos puestos de trabajo respecto de tres grupos educativos, divididos, por razones de normalización, según la contribución del grupo educativo total al nuevo empleo. Este indicador puede interpretarse como la demanda laboral relativa (de parte de las empresas) hacia los grupos de la fuerza de trabajo con diferentes niveles educativos. Un valor positivo implica que los asalariados contribuyeron más a los nuevos empleos del grupo educativo correspondiente, un valor negativo indica que lo hicieron los no asalariados.

Como se observa, en Bolivia, Brasil, Colombia, Chile y Perú existe una correlación positiva bastante fuerte entre el nivel educativo y la demanda laboral relativa de las empresas. La excepciones son Argentina y Costa Rica. En Argentina, en el grupo de menor nivel educativo cayeron tanto el número absoluto de los asalariados como el de los no asalariados, por lo

GRAFICO 4

América Latina (siete países): Demanda laboral relativa según nivel de educación

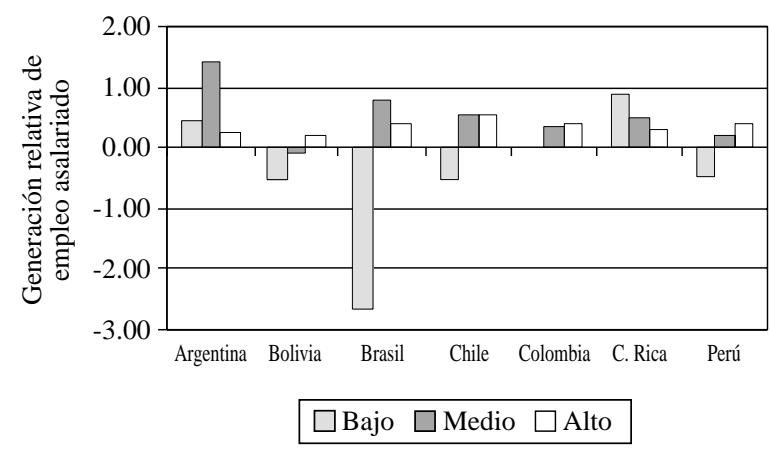

Fuente: Elaboración propia. 
que el valor positivo no implica preferencia de la demanda laboral de las empresas hacia este grupo de trabajadores. Sólo en Costa Rica se registró una fuerte demanda laboral relativa de personal del segmento educativo más bajo.

Durante los años noventa en general se profundizó la segmentación laboral según el nivel educativo: mientras la demanda estaba sesgada y favorecía a la fuerza trabajadora laboral con más años de estudio, el personal de menor escolaridad tenía más dificultades para encontrar empleo asalariado y se concentraba en mayor grado en las actividades no asalariadas.

¿Dónde se originó la demanda creciente de personal con alta calificación? Para precisarlo se hizo una descomposición de los cambios del empleo asalariado con el fin de diferenciar, por una parte, la contribución de los cambios ocurridos dentro de las ramas de actividad y, por otra, la contribución de los cambios entre las ramas de actividad (cuadro 5). Con tales fines se aplicó el siguiente cálculo respecto al personal de alto nivel educativo (13 años y más): ${ }^{18}$

$$
\Delta S=\sum_{i=1}^{n} \Delta A_{i} \bar{S}_{i}+\sum_{i=1}^{n \Delta S_{i} \bar{A}_{i}}
$$

para $i=1 \ldots, n$ ramas de actividad

donde:

$S=$ proporción de personal con alto nivel educativo en el empleo asalariado total

$S_{i}=$ proporción de personal con alto nivel educativo en la rama de actividad $i$

$A_{i}=$ empleo asalariado en la rama i como proporción del empleo asalariado total

${ }^{18}$ Adaptado de Berman, Bound y Griliches (1994).

CUADRO 5

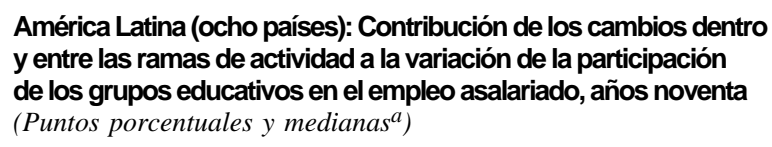

Total ${ }^{\text {b }}$ Dentro de la rama ramas las

A. Asalariados de alto nivel educativo (13 años y más)

Total

1.64

0.02

Agricultura

Industria manufacturera

Electricidad, gas, agua

Construcción

Comercio, hoteles y restaurantes

Transporte y comunicaciones

Servicios financieros, servicios a las empresas y otros

Servicios comunales y otros
0.05

0.01

0.01

0.19

0.04

0.23

1.09
0.63

2.27

$-0.03$

$-0.15$

$-0.02$

$-0.01$

0.13

0.01

0.45

0.27
$-0.01$

$-0.10$

$-0.01$

0.00

0.32

0.05

0.68

1.36

B. Asalariados de bajo nivel educativo (hasta 8/9 años)

Total

Agricultura

Industria manufacturera

Electricidad, gas, agua

Construcción

Comercio, hoteles y restaurantes

Transporte y comunicaciones

Servicios financieros, servicios a las empresas y otros

Servicios comunales y otros

-3.45
-0.01
-0.53
-0.11
-0.19
-0.89
-0.37
-0.09
-1.25

Fuente: Elaboración propia.

a Un valor positivo representa una contribución de igual signo al aumento de la participación del grupo en cuestión; un valor negativo una contribución en el sentido opuesto.

b Suma de las dos columnas. 
En la ecuación, las barras indican los promedios de los valores correspondientes para los años iniciales y finales. De esta manera, el primer término del lado derecho de la ecuación capta la contribución de los cambios entre las ramas (es decir, las diferencias con respecto al crecimiento del empleo asalariado), mientras que el segundo término capta la contribución de los cambios dentro de la rama (esto es, las variaciones de la participación del personal altamente calificado en el empleo asalariado de la rama).

En la mediana de ocho países la participación del personal altamente calificado en el empleo asalariado aumentó en 2.3 puntos porcentuales. Como muestra la primera parte del cuadro 5 , los cambios dentro de las ramas contribuyeron en mayor proporción a este aumento. ${ }^{19}$ Sin embargo, tuvieron importancia también los cambios entre las ramas - la reestructuración del empleo hacia actividades que ocupan mano de obra más calificada y la menor participación de ramas que, en términos generales, exigen menores niveles de calificación.

En cuanto a la contribución de las diferentes ramas de actividad al aumento del personal calificado, no sorprende el impacto negativo de los cambios entre ramas, debido al descenso de la participación de la industria manufacturera en el empleo asalariado. Sin embargo, los cambios internos en el sector no contribuyeron significativamente a la demanda de personal de alto nivel educativo. Esto confirma los resultados de otros estudios, conforme a los cuales las transformaciones productivas en este sector no han redundado (todavía) en una importante recomposición neta hacia un mayor nivel de calificación. Si bien la reestructuración llevó frecuentemente a una reducción del personal de baja calificación, también se han eliminado puestos de trabajo calificado, por ejemplo, en departamentos de investigación y desarrollo (véase Katz, 2000). De esta manera, el posible aumento de la demanda de personal calificado con la introducción de nuevas tecnologías se vio parcialmente contrarrestado por la eliminación de otros puestos de alta calificación. En consecuencia, los cambios internos del sector contribuyeron muy poco al aumento de la participación de los asalariados altamente calificados. Como, además, el retroceso de la participación del sector en el empleo asalariado se tradujo en una destrucción de oportunidades laborales para el personal de este grupo, la trans-

\footnotetext{
19 Se optó por la mediana y no por el promedio simple para evitar el impacto muy fuerte de los casos atípicos en el resultado.
}

formación de la industria manufacturera tuvo un impacto negativo en su demanda laboral.

En las actividades terciarias, principal sector en términos de generación de empleo, los nuevos puestos de trabajo asalariado se crearon en su gran mayoría para personal de niveles educativos medios altos y altos. En el gráfico 5 se resumen las características de la generación de empleo asalariado en el sector terciario, concentrada en los niveles intermedios y altos de escolaridad.

Los puestos para personal en el tramo más alto se concentraron en los servicios financieros, seguros, bienes raíces, servicios a las empresas y servicios comunales, sociales y personales. En cambio, en el rubro de comercio, restaurantes y hoteles y en el de servicios básicos (debido, sobre todo, al transporte) la demanda se concentró en personas con un nivel educativo intermedio. El empleo para el personal de más bajas calificaciones se generó en las ramas de comercio, restaurantes y hoteles y servicios comunales, sociales y personales. Así pues, en estas dos últimas ramas se registró la mayor heterogeneidad del empleo asalariado, con nuevos puestos de trabajo correspondientes a todo el espectro educativo. En cambio, las dos ramas más estrechamente vinculadas con los procesos de modernización - los servicios básicos, por un lado, y los servicios financieros, seguros, bienes raíces y servicios a las empresas, por el otro- generaron muy

GRAFICO 5

América Latina (ocho países): Composición de los nuevos puestos de trabajo asalariado en actividades terciarias, según nivel educativo y rama (Promedios simples) $^{a}$

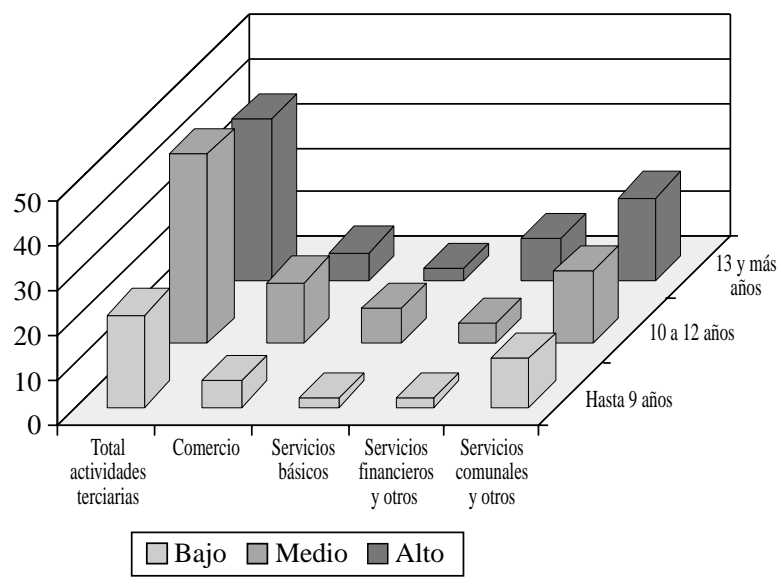

Fuente: Elaboración propia.

a Se trata de promedios simples de ocho países. 
pocos puestos de trabajo para personal de menor nivel educativo, puestos que se concentraron en el nivel medio (primer caso) y en el alto (segundo caso).

Las actividades terciarias presionaron la demanda laboral hacia niveles más altos de calificación, ya sea porque sus características de organización o tecnología los requieren, o porque con el aumento de los niveles de instrucción de la población activa se escoge el personal más calificado, aunque no sea estrictamente necesario. La transformación del sector terciario fue la causa principal tanto del aumento del personal calificado en las ramas de actividad - lo que contribuyó en gran proporción al aumento del personal calificado en el empleo asalariado- como de los incrementos originados por los cambios entre las ramas. Esto da por tierra la hipótesis según la cual, gracias a la apertura, el cambio tecnológico y la inversión en maquinaria y equipo, fueron, sobre todo, los sectores productores de bienes transables los que empujaron la modernización y el mejoramiento de la calidad de la estructura ocupacional (Lora y Olivera, 1998, p. 22).

Se suele suponer que hay una alta complementariedad entre el capital y la mano de obra calificada. En consecuencia, la inclinación de la demanda laboral por el personal más calificado coincidiría con una mayor intensidad en el uso de capital (K/L). Sin embargo, Morley (2000) no encontró que ésta hubiera aumentado durante los años noventa. Debido a que la relación $\mathrm{K} / \mathrm{L}$ es más baja en muchas actividades terciarias que en las secundarias (lo que no excluye la existencia de un alto coeficiente en algunos rubros, sobre todo en los servicios básicos), el aumento de la demanda laboral de personal calificado no se reflejó en un uso más intensivo de capital. En la industria manufacturera se observa hasta ahora un aumento relativo de la proporción del personal calificado, causado más bien por la reducción del personal de menor calificación.

Aplicando el mismo cálculo para descomponer el descenso de la participación del personal con niveles educativos relativamente bajos, de hasta 8 ó 9 años de estudio, según los datos disponibles (cuadro 5, parte B), se encontró que ese descenso también se había debido principalmente a los cambios internos en las diferentes ramas de actividad. Cerca de $80 \%$ de la caída de 4.2 puntos porcentuales de la participación de este grupo en el empleo asalariado puede atribuirse a variaciones de tal tipo. Este movimiento se originó en gran parte en el cambio de la composición de la oferta laboral (salida de personas de mayor edad con niveles educativos más bajos). La mayor parte de la reducción del empleo asalariado de personal de bajo nivel educativo causado por cambios dentro de las ramas se concentró en las actividades terciarias, lo que sería la otra cara del proceso de mejoramiento de la estructura laboral antes mencionado. También los cambios en la industria manufacturera hicieron una contribución importante. Como en este caso no se registraron aumentos netos de personal altamente calificado, durante el período analizado en muchos países la reestructuración laboral del sector se tradujo aparentemente, en forma concentrada, en una reducción del personal de baja calificación, sin fuertes procesos simultáneos de mejoramiento de los puestos de trabajo. Esta reestructuración del empleo parece reflejar una fase con predominio de estrategias defensivas de las empresas, orientadas a mejorar la competitividad sin grandes inversiones (Moguillansky y Bielschowsky, 2000), cuando en general dan escasa prioridad a la calificación de los recursos humanos (Palomares y Mertens, 1993).

Con respecto a los cambios entre las ramas, el descenso de la participación en el empleo asalariado de la agricultura y la industria manufacturera — dos de las ramas que tradicionalmente han empleado en mayor proporción mano de obra poco calificada - implicó la destrucción de puestos de trabajo para este grupo. ${ }^{20}$ Por otra parte, a pesar de la inclinación de la demanda laboral del sector terciario por el personal de alta calificación, la expansión de algunas actividades terciarias generó nuevos puestos de trabajo también para personal de menor nivel educativo (véase nuevamente el gráfico 5).

En conjunto, al comportamiento de las principales ramas de bienes transables, que tradicionalmente han concentrado gran parte del empleo asalariado para personas de menor nivel educativo, debe atribuirse casi la mitad del descenso de la participación de este grupo en el empleo asalariado (sobre todo por la reducción del peso relativo de estas ramas en el empleo asalariado), mientras que a las actividades terciarias, que típicamente han empleado menos mano de obra de este grupo, debe atribuirse la otra mitad (a causa de los procesos internos de ascenso laboral).

\footnotetext{
${ }^{20}$ No fue así en otra rama típicamente empleadora de este estrato de la fuerza laboral, la construcción.
} 


\section{IV}

\section{Tendencias de la heterogeneización}

\section{y la precarización}

Se esperaba que las reformas redundarían en una homogeneización de los mercados de trabajo, en términos de una reducción de las diferencias salariales por grado de instrucción, mejoramiento relativo de la posición de la pequeña y microempresa y una mayor formalización de las relaciones laborales.

\section{Las diferencias salariales por nivel educativo}

Identificada la preferencia de la demanda laboral por el personal de mayor calificación, no sorprende que los datos confirmen los resultados de otros autores sobre el aumento reciente de las diferencias salariales en la mayoría de los países. ${ }^{21}$ En seis de ocho países estudiados las diferencias salariales entre los ocupados con algunos estudios universitarios se elevaron en mayor o menor grado respecto al promedio salarial y, más aún, respecto a un grupo de referencia con alrededor de ocho años de estudios (cuadro 6). Las únicas excepciones fueron Brasil y Costa Rica. Esto implica que la demanda laboral diferenciada más que compensó el impacto del mejoramiento educativo de la oferta, ocurrido durante este período.

Un factor que reforzó la tendencia a la ampliación de las diferencias fue la política del salario mínimo, la cual ha sido conservadora en la mayoría de los países de la región, lo que se traduce en una diferencia creciente entre el salario mínimo y el salario medio reales en las empresas formales. ${ }^{22}$ Hay muchos indicios de que la diferencia salarial se amplió también en las empresas de cierto tamaño y formalidad. ${ }^{23}$ A ello posiblemente contribuyó el decaimiento del poder de negociación de los sindicatos, tendencia bastante generalizada en la región durante el último período.

En los países donde se amplió la diferencia salarial, los asalariados con niveles educativos más bajos

\footnotetext{
${ }^{21}$ Por ejemplo, véase, Robbins (1996) y Lora y Olivera (1998)

${ }^{22}$ Véase la información sobre la evolución de los salarios medios y mínimos en CEPAL (2000b y años anteriores).

${ }_{23}$ Véanse Saavedra (1999), sobre las empresas formales en Perú, Ramírez y Núñez (2000) sobre la industria manufacturera en Colombia y Weller (2000) sobre la industria manufacturera en México y las empresas formales en Chile.
}

participaron en menor grado en el aumento del salario real o sufrieron pérdidas mayores en el caso de una reducción (cuadro 7). Los datos no son comparables entre los países, ya que reflejan diferentes fases del ciclo económico. Por ejemplo, en Brasil, los salarios reales comenzaron a recuperarse a partir de 1992, luego de una profunda caída, y sólo en 1996 alcanzaron los niveles de 1990 (CEPAL, 2000b, cuadro VI.4). En cambio, la caída de los salarios en México reflejó en gran parte el impacto de la crisis de 1994-1995. De todas maneras, los datos presentados en el cuadro muestran interesantes resultados sobre la evolución de los salarios de los grupos por nivel de instrucción. En Bolivia y Perú los salarios medios de los grupos educativos más bajos casi se estancaron, y los aumentos salariales se limitaron a los grupos altos (Bolivia) o medios y altos (Perú). En Chile, los salarios reales subieron para todos los grupos, pero también con marcadas diferencias entre los niveles educativos. En estos tres países, es de señalar que el grupo educativo más bajo (0 a 3 años de estudio) tuvo un mejor resultado que los grupos inmediatamente siguientes. Posiblemente la causa resida en la política salarial, que en los tres países en los períodos correspondientes elevó el salario mínimo por encima del salario medio.

Como se vio anteriormente (cuadro 6), también en Colombia y México, como en los países recién mencionados, la diferencia salarial se amplió en los períodos correspondientes. En estos casos, la causa fue una caída del salario medio que afectó en forma más marcada a los grupos de bajos niveles educativos que a los de mayor escolaridad. Como se mencionó previamente, en dos países, Brasil y Costa Rica, no se amplió la diferencia salarial. En Brasil hubo una fuerte y generalizada recuperación de los salarios, y en Costa Rica todos los estratos - con excepción del grupo con menos instrucción- obtuvieron un aumento muy pequeño, pero parejo, del salario real.

Cabe concluir que, en la mayoría de los países, los grupos de niveles educativos bajos y medios bajos participaron sólo escasamente en las mejoras de salarios o sufrieron pérdidas más fuertes allí donde se deterioró la situación salarial general. En algunos ca- 
CUADRO 6

América Latina (ocho países): Salario relativo por nivel educativo, años noventa

\begin{tabular}{lcccc}
\hline País y período $^{\mathrm{a}}$ & \multicolumn{2}{c}{$\begin{array}{c}\text { Salario universitarios } \\
\text { promedio }\end{array}$} & \multicolumn{2}{c}{$\begin{array}{c}\text { Salario universitarios: } 7 \text { a } 9 \text { años } \\
\text { de educación }\end{array}$} \\
\cline { 2 - 5 } & Año 1 & Año 2 & Año 1 & Año 2 \\
\hline Argentina, 1991-1997 & 164.3 & 169.6 & 218.3 & 227.9 \\
Bolivia, 1989-1996 & 235.0 & 292.9 & 251.8 & 506.4 \\
Brasil, 1992-1997 & 380.2 & 383.5 & 553.2 & 553.3 \\
Chile 1990-1996 & 231.6 & 247.9 & 366.1 & 448.6 \\
Colombia, 1988-1995 & 222.2 & 261.6 & 276.7 & 327.2 \\
Costa Rica, 1990-1996 & 285.0 & 273.2 & 323.1 & 316.7 \\
México, 1991-1997 & 182.1 & 232.1 & 160.1 & 302.2 \\
Perú, 1991-1997 & 220.7 & 275.0 & 321.0 & 403.1 \\
Mediana & 226.9 & 267.4 & 298.9 & 365.2 \\
\hline
\end{tabular}

Fuente: Elaboración propia.

a Los datos se refieren al total nacional, con la excepción de Argentina (áreas urbanas), Bolivia (ciudades capitales de departamento y El Alto) y Brasil (seis áreas metropolitanas).

b El grupo de comparación en Argentina es el de educación primaria completa; en Bolivia el de nivel intermedio completo (ciclo básico con cinco años); y en México el de educación secundaria completa (primaria con seis años).

CUADRO 7

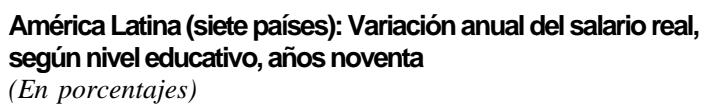

\begin{tabular}{|c|c|c|c|c|c|c|c|}
\hline \multirow[t]{2}{*}{ País y período ${ }^{\mathrm{a}}$} & \multicolumn{7}{|c|}{ Años de estudio ${ }^{b}$} \\
\hline & 0 a 3 & 4 a 6 & 7 a 9 & 10 a 12 & 13 a 15 & 16 y más & Total \\
\hline Bolivia, 1989-1996 & 0.6 & -0.1 & -0.8 & 1.0 & 8.0 & 5.6 & 3.2 \\
\hline Brasil, 1992-1997 & 5.6 & 6.2 & 7.6 & 6.4 & 5.4 & 7.6 & 7.4 \\
\hline Chile, 1990-1996 & 3.3 & 1.1 & 2.0 & 3.7 & 4.1 & 5.5 & 4.3 \\
\hline Colombia, 1988-1995 & -5.8 & -2.9 & -1.3 & -0.8 & 0.1 & 1.1 & -1.3 \\
\hline Costa Rica, 1990-1996 & -0.7 & 0.7 & 1.0 & 1.0 & 1.0 & 0.6 & 1.3 \\
\hline México, 1991-1997 & -7.4 & -6.4 & -10.6 & -2.7 & \multicolumn{2}{|c|}{-1.3} & -5.3 \\
\hline Perú, 1991-1997 & 1.1 & -1.3 & 3.1 & 2.7 & 4.3 & 7.1 & 3.2 \\
\hline
\end{tabular}

Fuente: Elaboración propia.

a Los datos se refieren al total nacional, con excepción de Argentina (áreas urbanas), Bolivia (ciudades capitales de departamento y El Alto) y Brasil (seis áreas metropolitanas).

b Las categorías para Bolivia son: i) hasta ciclo básico incompleto; ii) ciclo básico completo; iii) hasta ciclo intermedio completo; iv) ciclo medio y técnico medio; v) escuela normal, técnico superior incompleto, universitario incompleto; vi) técnico superior completo y universitario completo. Las categorías para Chile son: hasta 3 años, de 4 a 7, 8, de 9 a 11, 12, 13 años y más.

sos, la política salarial activa parece haber atenuado esta tendencia para el grupo de menos instrucción.

\section{La diferencia entre las microempresas y las empresas de mayor tamaño}

En los años ochenta, la caída de los salarios reales en el sector formal fue en general mayor que en las microempresas, con lo cual la diferencia de salarios entre ambos tipos de empresa tendió a reducirse (cuadro 8).
En los años noventa la diferencia de salarios entre las microempresas y las empresas formales aparentemente volvió a aumentar en la mayoría de los países (cuadro 8). El trasfondo de estas tendencias parece ser la estrategia de muchas empresas de mayor tamaño de bajar costos reduciendo el empleo, lo cual, en el marco de importantes incrementos de productividad, dio lugar a aumentos salariales en las actividades formales. En cambio, en las microempresas se creó una elevada proporción de nuevos puestos de trabajo, pero con 


País $\begin{gathered}\text { Período (primer año, año } \\ \text { intermedio y año final) }\end{gathered}$

Relación entre los salarios de no profesionales y no técnicos, en establecimientos de hasta 5 personas y de más de 5 personas

\begin{tabular}{ccc}
\hline Años ochenta & $\begin{array}{c}\text { Principios de los } \\
\text { años noventa }\end{array}$ & $\begin{array}{c}\text { Mediados de los } \\
\text { años noventa }\end{array}$
\end{tabular}

\begin{tabular}{llccc}
\hline Argentina $^{\mathrm{a}}$ & $1980-1990-\ldots$ & 1.3 & 1.3 & $\ldots$ \\
Bolivia $_{\text {Brasib }}^{\mathrm{b}}$ & $1989-1992-1997$ & 1.4 & 1.2 & 1.4 \\
Chile $^{\mathrm{a}}$ & $1979-1990-1996$ & 1.6 & 1.4 & 1.6 \\
Costa Rica $_{\text {Méxicoc }}^{\text {ac }}$ & $\ldots-1992-1996$ & $\ldots$ & 1.4 & 1.7 \\
Perúc $^{\mathrm{c}}$ & $1981-1990-1997$ & 1.5 & 1.7 & 1.5 \\
\end{tabular}

Fuente: Elaborado por el autor sobre la base de Panorama social de América Latina (CEPAL, varios años) .

a Incluye asalariados públicos.

b Se comparan los salarios medios de los asalariados con y sin contrato de trabajo.

c Incluye profesionales y técnicos, total nacional.

pocas oportunidades de mejorar las condiciones laborales, específicamente los salarios.

A pesar del aumento de la diferencia de salarios entre las microempresas y las empresas más grandes (reflejo de una creciente diferencia de productividad), se han desarrollado también actividades de un grado apreciable de calificación en unidades más pequeñas; esto indica que la expansión de la microempresa no se ha basado sólo en la proliferación de unidades de supervivencia, sino que también surgieron establecimientos de tamaño muy pequeño con un nivel tecnológico y de capital humano no desdeñable, los cuales se benefician de las posibilidades que abren las nuevas tecnologías para las unidades de menor tamaño (Weller, 2000, sección 6.D).

\section{Las diferencias de salario entre hombres y mujeres}

En todos los países estudiados existe una diferencia de salario entre hombres y mujeres, tanto a nivel agregado como en los diversos niveles educativos. Durante los años noventa esta diferencia se redujo en todos los países (cuadro 9). En algunos casos (Bolivia, Colombia y México) influyó en este resultado una fuerte incorporación de mujeres de alto nivel educativo, la que no sólo superó el ascenso del nivel educativo entre los hombres, sino que también reforzó la tendencia a una mayor participación de mujeres con altos niveles educativos entre las asalariadas que en el caso de los hombres. Esta diferencia se explica en gran parte por la dificultad de muchas mujeres con menos instrucción, que suelen contar con menores medios económicos, para trabajar como asalariada, sobre todo si son madres. ${ }^{24}$ Por otro lado, la mayor expansión del empleo en las actividades terciarias estimuló la incorporación laboral de mujeres de alto nivel educativo. ${ }^{25}$ En estas ramas su participación laboral sobrepasa el promedio y durante los años noventa en muchos países las mujeres aumentaron esta participación aún más. Además, la expansión del empleo en estas ramas fue acompañada por importantes procesos de mejora de su nivel de calificación.

Aparte del mayor aumento del nivel educativo entre las mujeres que entre los hombres, en cierto grado también las menores diferencias salariales en algunos niveles educativos parecen haber contribuido a la evolución positiva a nivel agregado. En efecto, entre hombres y mujeres asalariadas con estudios universitarios completos, en que la diferencia salarial por género suele ser mayor, se registró una tendencia general a la reducción de esta disparidad en Brasil, Colombia, Costa Rica, Chile y Perú; sólo en México subió ligeramente. Un panorama parecido se observa entre

\footnotetext{
${ }^{24}$ Por ello, la participación laboral suele ser mucho más polarizada entre las mujeres de nivel educativo y estratos económicos bajo y alto que entre los hombres; véase Jiménez y Ruedi (1998).

${ }^{25}$ Véanse CEPAL, 1998, y Marinakis (1999). Si bien la proporción de mujeres que trabajan en el sector informal es más alta que la de hombres, la informalización de los años noventa afectó algo menos a las mujeres: entre 1990 y 1998 el porcentaje de las mujeres ocupadas en zonas urbanas que se desempeñan en el sector informal subió de $49.2 \%$ a $52.0 \%$, mientras que para los hombres las proporciones fueron $41.1 \%$ y $45.0 \%$ (огт, 1999a, p. 58).
} 
CUADRO 9

América Latina (ocho países): Transformación de la incorporación laboral de las mujeres, según nivel de calificación y salarios relativos, años noventa

\begin{tabular}{|c|c|c|c|c|c|c|c|}
\hline \multirow[t]{2}{*}{ País y período } & \multicolumn{2}{|c|}{$\begin{array}{c}\text { Participación de personal } \\
\text { con estudios universitarios } \\
\text { en el empleo asalariado } \\
\text { de las mujeres }\end{array}$} & \multicolumn{2}{|c|}{$\begin{array}{l}\text { Diferencia salarial } \\
\text { hombres/mujeres } \\
(\text { en } \%)\end{array}$} & \multicolumn{3}{|c|}{$\begin{array}{c}\text { Variación de la diferencia de salarios } \\
\text { hombres/mujeres entre año } 1 \text { y año } 2 \\
(\text { en } \%)\end{array}$} \\
\hline & Año 1 & Año 2 & Año 1 & Año 2 & $\begin{array}{l}\text { 4-6 años de } \\
\text { educación }\end{array}$ & $\begin{array}{l}\text { 7-9 años de } \\
\text { educación }\end{array}$ & $\begin{array}{c}16 \text { y más } \\
\text { años }\end{array}$ \\
\hline Bolivia, 1989-1996 & 17.9 & 23.0 & 137.3 & 125.0 & $\ldots$ & $\ldots$ & $\ldots$ \\
\hline Chile, 1992-1996 & 34.6 & 34.7 & 132.8 & 127.5 & -17.6 & +3.1 & -8.2 \\
\hline Colombia, 1988-1995 & 14.8 & 18.8 & 167.6 & 133.1 & -23.6 & +9.2 & -10.4 \\
\hline Costa Rica, 1990-1996 & 18.3 & 23.3 & 121.6 & 120.8 & +0.5 & -4.9 & -17.2 \\
\hline México, 1991-1997 & 14.6 & 19.2 & 137.5 & 121.6 & -8.8 & -14.1 & +2.0 \\
\hline Perú, 1991-1997 & 33.5 & 32.2 & 132.3 & 132.4 & -5.1 & +11.6 & -20.6 \\
\hline
\end{tabular}

Fuente: Elaboración propia.

a Los datos se refieren al total nacional, con la excepción de Bolivia (ciudades capitales de departamento y El Alto) y Brasil (seis áreas metropolitanas).

los asalariados con 4 a 6 años de estudio; en cambio, la evolución de la diferencia de salarios entre hombres y mujeres con alrededor de ocho años de estudios fue más heterogénea, pues aumentó en Colombia, Chile y Perú y se redujo en Brasil, Costa Rica y México.

\section{La calidad del empleo asalariado}

En los análisis de la situación laboral en América Latina y el Caribe hay conciencia de que no basta con evaluar la cantidad de puestos de trabajo generados, sino que hay problemas de calidad que deben tomarse en cuenta. Estos surgen en parte porque muchos empleos se crean cediendo a la presión de la oferta laboral que obliga a muchas personas económicamente activas a aceptar malas condiciones de trabajo con tal de percibir un ingreso. Otras fuentes pueden ubicarse en las características de la demanda (bajos niveles tecnológicos que implican una baja productividad) y de la institucionalidad laboral (bajos niveles de protección social o incumplimiento de las normas existentes).

Aunque las encuestas que dan cuenta de los cambios en el mercado laboral no utilizan todas los mismos indicadores, la información disponible estaría indicando una tendencia al deterioro de la calidad, en función de la estabilidad laboral y la seguridad social (cuadro 10). ${ }^{26}$ En varios países (Argentina, Bolivia,

\footnotetext{
26 Para un detallado análisis conceptual y empírico de la calidad del empleo, véase Infante (1999) y para tendencias de diversos indicadores de calidad del empleo CEPAL (2000b, anexo estadístico); sobre la cotización en el seguro social véase oIT (1999a, p. 63 y siguientes).
}

CUADRO 10

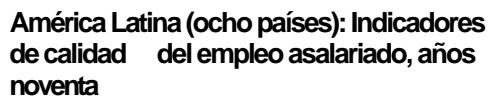

\begin{tabular}{|c|c|c|c|}
\hline País y períodos ${ }^{\mathrm{a}}$ & Indicador & Año 1 & Año 2 \\
\hline \multirow[t]{3}{*}{ Argentina, 1991-1997 } & Registrado & 63.2 & 58.8 \\
\hline & - hombres & 68.8 & 62.7 \\
\hline & - mujeres & 55.7 & 53.1 \\
\hline \multirow[t]{3}{*}{ Bolivia, 1989-1996 } & Contrato permanente & 78.8 & 76.7 \\
\hline & - hombres & 76.0 & 74.4 \\
\hline & - mujeres & 86.5 & 81.7 \\
\hline \multirow[t]{3}{*}{ Brasil, 1992-1997 } & Con carteira & 68.8 & 64.7 \\
\hline & - hombres & 71.5 & 67.0 \\
\hline & - mujeres & 64.5 & 62.9 \\
\hline \multirow[t]{3}{*}{ Chile, 1990-1996 } & Con contrato & 82.0 & 76.1 \\
\hline & - hombres & 82.4 & 77.5 \\
\hline & - mujeres & 81.0 & 73.4 \\
\hline Colombia, 1991-1997b & Trabajo permanente & 81.8 & 78.9 \\
\hline \multirow[t]{3}{*}{ Costa Rica, 1990-1996c } & Alta calidad & 55.6 & 42.6 \\
\hline & - hombres & 56.0 & 46.5 \\
\hline & - mujeres & 54.7 & 34.3 \\
\hline México, 1990-1997 & Con prestaciones & 79.5 & 75.3 \\
\hline \multirow[t]{3}{*}{ Perú, 1991-1997d } & Con seguro social & 51.2 & 26.9 \\
\hline & - hombres & 52.0 & 26.7 \\
\hline & - mujeres & 49.4 & 27.4 \\
\hline
\end{tabular}

Fuente: Elaboración propia.

a Los datos se refieren al total nacional, con la excepción de Argentina (áreas urbanas), Bolivia (ciudades capitales de departamento y El Alto), Brasil (seis áreas metropolitanas) y Colombia (siete áreas metropolitanas).

b Total de ocupados.

c La calidad del empleo en Costa Rica se midió a base de un indicador para el cual se tomó en cuenta el cumplimiento de la ley respecto al salario mínimo, afiliación al seguro social y la estabilidad del empleo (véase Montiel, 1999).

d Sólo asalariados privados. 
Brasil, Colombia , Chile) descendió el número de contratos sin plazo o incluso del trabajo asalariado con contrato; en otros (México, Perú) se advierte una menor cobertura de la seguridad social. ${ }^{27} \mathrm{El}$ empeoramiento de la calidad media del empleo asalariado afectó tanto a los hombres como a las mujeres, man- teniéndose así las diferencias de calidad del empleo entre hombres y mujeres. Este empeoramiento se debió, en parte, a la flexibilización de la institucionalidad laboral con la cual se buscaba hacer frente a las nuevas condiciones de los mercados (Weller, 2000, cap. 7).

\section{V}

\section{Conclusiones y perspectivas}

Los problemas laborales de los años noventa no se deben a un crecimiento sin empleo, sino a la debilidad del proceso de crecimiento económico, agravada por el uso menos intensivo de mano de obra, como efecto principalmente de las transformaciones de las actividades productoras de bienes transables. Se limitó así la demanda laboral, mientras la presión desde el lado de la oferta generaba una alta proporción de empleo no asalariado. Ello no alcanzó a compensar la escasa creación de empleo asalariado, por lo que el desempleo siguió una tendencia ascendente y, hacia fines de la década, alcanzó niveles superiores incluso a los de la crisis de la deuda de los años ochenta. Al revés de lo esperado, las reformas económicas tuvieron un impacto contradictorio, pues mientras estimulaban el crecimiento y, por lo tanto, la demanda laboral, reducían la intensidad del uso de la fuerza laboral.

Tampoco se cumplieron las expectativas respecto a la evolución sectorial del empleo y sus características. La modernización productiva de las empresas en muchos rubros así como la reestructuración sectorial en favor de las actividades terciarias influyen ambas en una mayor segmentación del mercado de trabajo, sobre la base del nivel educativo, pues la demanda laboral mostró una clara inclinación a favor del personal con escolaridad media y alta. En consecuencia, las personas con menos instrucción formal tuvieron menor acceso al empleo asalariado y se amplió la diferencia de salarios entre los trabajadores calificados y los no calificados. Aumentaba también la distancia entre las microempresas y las más grandes y, en el contexto de una flexibilización de las relaciones laborales, los indicadores de calidad del empleo tendieron a empeorar. Todas estas tendencias son contrarias a las

27 Véase también Tokman y Martínez, eds. (1999). expectativas cifradas en las reformas. La única excepción a las tendencias de polarización observadas en los mercados de trabajo de la región fue la reducción de la diferencia de salarios entre hombres y mujeres.

La reestructuración sectorial del empleo ayudó a desencadenar un proceso de heterogeneización del mercado de trabajo. Por un lado, se produjo un proceso simultáneo e importante de generación de empleo en los extremos de la estructura laboral, con procesos de ascenso (creciente demanda de personal altamente calificado) y concentración del empleo nuevo en segmentos que se caracterizan por una menor calidad (sector informal). Al propio tiempo, aumentó la diferencia de la productividad laboral media y de salarios entre las microempresas y las empresas de mayor tamaño, lo que parece indicar que aumenta la distancia que separa lo formal de lo informal. Por otro lado, también en el empleo formal (empresas medianas y grandes) se observa una heterogeneización de las condiciones laborales, tanto por ingresos (aumento de las diferencias salariales entre personal de diferentes niveles de calificación) como en lo que respecta a las relaciones laborales (surgimiento de núcleos estables de trabajadores frente a trabajadores de empleo inestable, con formas contractuales más precarias y menor protección social). Por último, se da una diferenciación interna en las microempresas y en el trabajo por cuenta propia, en un segmento de los cuales también se dan tendencias al mejoramiento de la estructura laboral.

¿Cuáles son las perspectivas de la demanda laboral y de la generación de empleo a nivel sectorial? El desempeño del sector agropecuario durante los años noventa y la experiencia internacional no permiten suponer que sea transitorio el saldo neto negativo en la generación de empleo. Aunque surgirán nuevos puestos de trabajo agropecuario con la diversificación de los cultivos y la ampliación de ciertas actividades, 
no serán muchos, por efecto de las características de utilización de los factores en muchas de las actividades dinámicas y su moderado crecimiento. Además, y sobre todo, en la mayoría de los países de la región gran parte de la población rural y agropecuaria pertenece a los estratos más pobres y un elevado número de la fuerza de trabajo agropecuaria puede ser caracterizado como subempleado visible (estacionalmente) o invisible. De esta manera se mantienen los factores de expulsión de mano de obra agropecuaria (sobre todo de jóvenes) y su orientación hacia actividades no agropecuarias, lo que corresponde a las tendencias seculares mundiales. La inversión de esta tendencia - un aumento neto del empleo agropecuario- en la mayoría de los países sería más bien expresión de la debilidad de los sectores no agropecuarios y de los factores de atracción correspondientes que son el reflejo del surgimiento de empleo productivo en el sector agropecuario. La superación de los escollos típicos de la agricultura campesina, tanto en la producción agropecuaria misma como en su entorno, aumentaría la productividad y los ingresos laborales antes que el empleo directo en el sector. Sin embargo, debido a los múltiples encadenamientos, una transformación del sector agropecuario de este tipo tendría un efecto positivo en el empleo rural en otras ramas.

En cuanto a las perspectivas del empleo manufacturero, hay esperanza fundada de que en el futuro el sector no se caracterizará por un crecimiento sin empleo. Al cumplirse la etapa de reestructuración, en la cual se cerraron muchas empresas mientras otras se concentraban en medidas defensivas y ahorradoras de mano de obra, estaría superado su impacto negativo inmediato y más fuerte en muchos países. Gracias a un aumento de la productividad y la competitividad, muchas empresas podrán competir con mayor éxito en los mercados internos y externos. Así, con la condición de solucionar los problemas macroeconómicos, la producción sectorial podría alcanzar tasas razonables de crecimiento, con un impacto favorable en el empleo. Esto vale tanto para las empresas más grandes como para las pequeñas y medianas, que se caracterizan por un uso más intensivo de mano de obra y por prosperar en un contexto expansivo.

Por el otro lado, la competencia global y la tendencia a adoptar una modalidad tecnológica ahorrativa de mano de obra impiden que el sector vuelva a ser el motor de generación de empleo que fue hasta los años setenta. La competencia, crecientemente de alcance mundial, limita la posibilidad de crecimiento en rubros de uso intensivo de mano de obra, y en otros manten- drá la presión de orientarse a soluciones óptimas (first best) que dejan cada vez menos posibilidad de adoptar otras combinaciones de factores. Siendo así, la tasa de generación de empleo será moderada, y a nivel regional la participación en el empleo seguirá bajando. ${ }^{28}$ Este proceso será más lento en los países del norte por las oportunidades de inversión y empleo industrial en el marco de la creciente integración con los mercados norteamericanos.

Con este trasfondo parece evidente que también en el futuro la gran mayoría de los nuevos puestos de trabajo tendrá que surgir en actividades terciarias. La expansión relativa tanto del producto como del empleo en este sector es una tendencia global y de largo plazo. No se trata simplemente de la escasa generación de empleo en los sectores primario y secundario, sino también del nuevo papel que les tocaría desempeñar a las actividades terciarias en la estructura económica. Por lo demás, la competitividad de los sectores tradicionales productores de bienes transables también depende crecientemente de la integración eficiente con servicios de múltiples tipos, como la investigación y el desarrollo tecnológico, los sistemas financieros y de comercialización y los servicios postventa. Otras áreas importantes para la competitividad sistémica, aunque en forma indirecta, que tienden a expandirse y a generar empleo en cantidad relevante y de buena calidad son la salud y la educación. La modernización de la estructura socioeconómica en su conjunto exige del sector terciario que cumpla un papel más destacado sobre todo en el conocimiento, con la generación del empleo correspondiente para personal de calificaciones medianas y altas. Sin embargo, las transformaciones en curso también pueden generar cantidades elevadas de empleo terciario para personal de niveles educativos intermedio y bajo, sobre todo en los servicios comunales y personales, comercio y hotelería, así como en ciertos servicios para las empresas (limpieza, banquetería, transporte, tratamiento de basuras, etc.).

Las transformaciones en curso complican el análisis de la evolución sectorial del empleo, ya que muchos de los instrumentos de medición utilizados tradicionalmente se vuelven insuficientes para captar sus efectos. En el análisis sectorial se torna cada vez más borrosa la distinción entre los sectores primario, secundario y terciario, lo que debilita el análisis del merca-

\footnotetext{
${ }^{28}$ Se seguiría así la pauta de los países industrializados y también de los "tigres" del este asiático; véase Rowthorn y Ramaswamy (1997).
} 
do del trabajo basado en las encuestas comúnmente utilizadas. Las transformaciones de la estructura productiva de las economías y de la organización de las empresas tienen efectos correspondientes en la estructura ocupacional. Por ejemplo, muchas empresas manufactureras aumentan el peso de las ocupaciones no directamente vinculadas con la producción, como la investigación, los servicios internos y los servicios al cliente. Por el contrario, la adopción de medidas de desintegración (exteriorización) de ciertas actividades puede reducir estadísticamente el número de los ocupados y afectar la productividad laboral media en estas empresas, sin que haya habido transformaciones productivas.

Estos procesos no sólo afectan la medición del empleo y la productividad por ramas de actividad; influyen también en otras variables de la medición y el análisis laboral, como el tamaño de las empresas y la categoría ocupacional. Por ejemplo, la subcontratación de personas o servicios puede transformar la composición de las categorías de ocupación, al convertir a trabajadores asalariados de empresas grandes en asalariados de empresas pequeñas o medianas, o en trabajadores por cuenta propia.

Así, también, los procesos de desintegración y recomposición productiva generan una estructura productiva - y laboral - mucho más heterogénea que la anterior. Específicamente, la sustitución de la organización vertical del proceso productivo en grandes empresas por redes o cadenas con múltiples vínculos con proveedores de todo tipo de insumos (bienes y servicios) en el interior y crecientemente en el exterior tiene un profundo efecto, de alcances y características todavía no muy bien comprendidos, sobre la generación de empleo y sus características.

Mientras las tendencias indicadas influyen en las perspectivas de la composición sectorial futura del empleo, el crecimiento económico es el determinante principal del nivel de la demanda laboral y, por lo tanto, del peso relativo de los distintos sectores del mercado de trabajo que son impulsados por la demanda y por la oferta. Cuando el crecimiento económico es insuficiente, un elevado porcentaje del empleo terciario se concentra en ocupaciones informales. Por estas razones, una política orientada a mejorar los mercados de trabajo tiene que preocuparse del nivel y la estabilidad de este crecimiento. Por otra parte, los problemas laborales de largo plazo y la tendencia hacia un uso menos intenso de la mano de obra obligan a idear instrumentos que fomenten a mediano plazo simultáneamente la producción competitiva y la generación de empleo productivo. ${ }^{29}$

Es probable que la tendencia hacia el aumento de las diferencias salariales se atenúe progresivamente en el futuro, con el aumento de la oferta laboral en aquellas ocupaciones que en estos momentos muestran un desequilibrio con respecto a la demanda. Sin embargo, tomando en cuenta que las nuevas pautas de producción imponen un uso más intensivo de tecnología y de capital humano que el sistema tayloriano vigente desde los primeros años de la posguerra, y que la demanda de mano de obra de baja calificación parecería seguir limitada, no cabe esperar reducciones importantes en las diferencias salariales en un futuro cercano. Aspectos relevantes también en este contexto son los elementos de la institucionalidad laboral, entre ellos el papel futuro que cumplirán los sindicatos, que suelen tener un impacto igualitario sobre la estructura salarial, o la política de salario mínimo, que si bien en la mayoría de los países ha sido conservadora, en otros ha elevado el piso salarial para los ocupados de nivel educativo más bajo.

\footnotetext{
${ }^{29}$ Véase Altenburg, Qualmann y Weller (1999) para una discusión de políticas de fomento de empleo productivo en diferentes áreas productivas, así como de políticas complementarias.
} 
Bibliografía

Altenburg, T., R. Qualmann y J. Weller (1999): Wirtschaftliche Modernisierung und Beschäftigung in Lateinamerika. Zielkonflikte und Lösungsansätze, Berlin, Deutsches Institut für Entwicklungspolitik.

Berman, E., J. Bound y Z. Griliches (1994): Changes in the demand for skilled labor within U.S. manufacturing: Evidence from the annual survey of manufactures, The Quarterly Journal of Economics, vol. CIX, issue 2, $\mathrm{N}^{\circ} 436$, Cambridge, Massachusetts, Harvard University.

BID (Banco Interamericano de Desarrollo) (1997): Progreso económico y social en América Latina. Informe 1997, Washington D.C.

CEPAL/CELADE (Comisión Económica para América Latina y el Caribe/Centro Latinoamericano de Demografía) (1999): América Latina. Proyecciones de población urbana-rural. Período 1970-2025, Boletín demográfico, año 32, Nº3, Santiago.

CEPAL (varios años): Panorama social de América Latina, Santiago de Chile.

(1997): La brecha de la equidad. América Latina, el Caribe y la cumbre social, LC/G.1954/Rev.1-P, Santiago de Chile. Publicación de las Naciones Unidas, $\mathrm{N}^{\mathrm{o}}$ de venta: S.97.II.G.11. (1998): Panorama social de América Latina, 1997, LC/G.1982-P, Santiago de Chile.

(2000a): Panorama social de América Latina, 1999-2000 LC/G.2068-P, Santiago de Chile.

(2000b): Estudio económico de América Latina y el Caribe 1999-2000, Santiago de Chile.

Duryea, S. y M. Székely (1998): Labor markets in Latin America: A supply-side story, presentado al seminario Employment in Latin America: What is the Problem and How to Address It?, Cartagena de Indias, BID, 15 de marzo.

Infante, R. (ed.) (1999): La calidad del empleo. La experiencia de los países latinoamericanos y de los Estados Unidos, Santiago de Chile, Organización Internacional del Trabajo (OIT).

Jiménez, L., F. y N. Ruedi (1998): Determinantes de la desigualdad entre los hogares urbanos, Revista de la CEPAL, $\mathrm{N}^{\circ} 66$, LC/G.2049-P, Santiago de Chile, CEPAL.

Katz, J.M. (2000): Reformas estructurales, productividad y conducta tecnológica en América Latina, Santiago de Chile, CEPAL.

Lora, E. y M. Olivera (1998): Macro policy and employment problems in Latin America, trabajo presentado al seminario Employment in Latin America: What is the Problem and How to Address It?, Cartagena de Indias, BID, 15 de marzo.

Marinakis, A. E. (1999): Género, pobreza y empleo en los países del Cono Sur: interrelaciones y estado de situación, Santiago de Chile, OIT, Equipo Técnico Multidisciplinario (ETM).

Moguillansky, G. y R. Bielschowsky (2000): Las reformas económicas y la inversión en América Latina: Un enfoque sectorial, Santiago de Chile, CEPAL.

Montiel Masís, N. (1999): Costa Rica: reformas económicas, sectores dinámicos y calidad de los empleos, serie Reformas económicas, $\mathrm{N}^{\circ} 26$, Santiago de Chile.

Morley, S. A. (2000): The Income Distribution Problem in Latin America, Washington, D.C., The Brookings Institution.

Morley, S. A., R. Machado y S. Pettinato (1999): Indexes of Structural Reform in Latin America, serie Reformas económicas, $\mathrm{N}^{\circ} 12$, Santiago de Chile, CEPAL.
OIT (1998a): Anuario de estadísticas del trabajo, Ginebra. (1998b): Panorama Laboral '98, Lima. (1999a): Panorama Laboral '99, Lima.

(1999b): Trabajo decente y protección para todos. Prioridad de las Américas, memoria del Director General, XIV Reunión Regional Americana, Lima, 24 al 27 de agosto.

Palomares, L. y L. Mertens (1993): Cambios en la gestión y actitud empresarial en América Latina. Un marco de análisis, Revista de economía y trabajo, año $1, \mathrm{~N}^{\circ} 2$, Santiago de Chile, Programa de Economía del Trabajo (PET).

Porter, M. E. (1990): La ventaja competitiva de las naciones, Buenos Aires, J. Vergara Editor, S.A.

PREALC (Programa Regional del Empleo para América Latina y el Caribe) (1991): Empleo y equidad: el desafío de los 90, Santiago de Chile.

Psacharopoulos, G. y Y. C. Ng (1992): Earnings and Education in Latin America, Assessing Priorities for Schooling Investments, The World Bank, Policy Research Working Papers, N 1056, Washington, D.C., Banco Mundial.

Ramírez, J. M. y L. Núñez (2000): Reformas, crecimiento, progreso técnico y empleo en Colombia, serie Reformas económicas, $\mathrm{N}^{\circ} 59$, Santiago de Chile, CEPAL.

Robbins, D. J. (1994): Relative wage structure in Chile, 1957-1992: Changes in the structure of demand for schooling, Estudios de economía, vol. 21, número especial, Santiago de Chile, Universidad de Chile, Departamento de Economía.

(1996): Evidence on Trade and Wages in the Developing World, Technical papers, $\mathrm{N}^{\circ} 119$, París, OCDE Development Centre.

Rowthorn, R. y R. Ramaswamy (1997): Deindustrialization: Its Causes and Implications, Economic issues, $\mathrm{N}^{\circ} 10$, Washington,D.C., Fondo Monetario Internacional (FMI).

Saavedra Chanduví, J. (1999): La dinámica del mercado de trabajo en el Perú antes y después de las reformas estructurales, serie Reformas económicas, $\mathrm{N}^{\circ} 27$, Santiago de Chile, CEPAL.

Stallings, B. y W. Peres (2000): Crecimiento, empleo y equidad: el impacto de las reformas económicas en América Latina y el Caribe, Santiago de Chile, CEPAL/ Fondo de Cultura Económica (FCE).

Thomas, J. (1997): El nuevo modelo económico y los mercados laborales en América Latina, V. Bulmer-Thomas (comp.), El nuevo modelo económico en América Latina. Su efecto en la distribución del ingreso y la pobreza, México, D. F., FCE.

Tokman, V.E. y D. Martínez, eds. (1999): Flexibilización en el margen: la reforma del contrato de trabajo, Ginebra, OIT.

Weeks, J. (1999): Salarios, empleo y derechos de los trabajadores en América Latina entre 1970 y 1998, Revista Internacional del Trabajo, vol. 118, $\mathrm{N}^{\circ} 2$, Ginebra, Oficina Internacional del Trabajo (OIT).

Weller, J. (2000): Reformas económicas, crecimiento y empleo: Los mercados de trabajo en América Latina, Santiago de Chile, CEPAL/FCE.

Wood, A. (1997): Openess and wage inequality in developing countries: The Latin American challenge to East Asian conventional wisdom, The World Bank Economic Review, vol. $11, N^{\circ} 1$, Washington, D.C., Banco Mundial. 